\title{
A sensitive bioassay for a nucleopolyhedrovirus using silkworms, Bombyx mori L., previously treated with a chitin synthesis inhibitor
}

\author{
Toru Arakawa ${ }^{1, *}$ and Mitsuyoshi Nozawa ${ }^{2}$ \\ ${ }^{1}$ National Institute of Agrobiological Sciences; Tsukuba, Ibaraki 305-8634, Japan \\ ${ }^{2}$ Institute of Sericulture; Ami, Ibaraki 300-0324, Japan \\ (Received 26 December 2003; Accepted 27 September 2004)
}

\begin{abstract}
A hypersensitive bioassay of nucleopolyhedrovirus infecting a silkworm, Bombyx mori, (BmNPV) has been developed. Peroral administration of a chitin synthesis inhibitor, Polyoxin AL wettable powder (Polyoxin AL), to a silkworm resulted in a decrease of the median lethal concentration $\left(\mathrm{LC}_{50}\right)$ of $\mathrm{BmNPV}$. The $\mathrm{LC}_{50}$ in the silkworm ingesting Polyoxin AL decreased as the silkworm developed from the 2 nd to the 4 th stadium. $\mathrm{LC}_{50}$ in a 2 nd stadium silkworm ingesting Polyoxin $\mathrm{AL}$ was lower than that in a silkworm refrigerated at $4{ }^{\circ} \mathrm{C}$. Silkworms at the 2 nd stadium that had ingested Polyoxin AL were used to detect BmNPV in the dust from 15 sericultural farmhouses. Dust samples were collected at a leaf storage space, a rearing room and a mounting room just before the beginning of silkworm rearing after the formalinisation of the rearing environment. The dust was collected again at the same places immediately after harvesting the cocoons. In addition to the BmNPV detection in the dust, occurrence of innerside-stained cocoons was examined at the same 15 farmhouses where the dust was collected. The following features of BmNPV contamination are recognized. In some farmhouses, BmNPV was not inactivated even after treatment with formalin. BmNPV accumulated in only one cycle of the silkworm rearing of about 3 weeks in almost all the farmhouses. Of all three places in which the dust was assayed, the mounting room tended to be most heavily contaminated by BmNPV. More innerside-stained cocoons occurred in a farmhouse where more silkworms died of BmNPV in an assay of the dust collected before the beginning of the silkworm rearing. On the other hand, these features of BmNPV contamination were not detected using silkworm larvae that had not ingested Polyoxin AL. This new bioassay for BmNPV utilizing Polyoxin AL-treated larvae is an effective tool to assess the cleanliness of the sericultural environment.
\end{abstract}

Key words: Bombyx mori; nucleopolyhedrovirus; bioassay; polyoxin

\section{INTRODUCTION}

A viral disease of the silkworm Bombyx mori often breaks out at sericultural farmhouses and decreases the cocoon harvest. The nucleopolyhedrovirus infecting the silkworm (BmNPV) is one of the major pathogens causing serious damage to sericulture. When the BmNPV infects the silkworm before the 5th day in the 5th stadium, the larva dies in the 5th stadium without spinning a cocoon. The silkworm larvae infected with the virus after the 6th day in the 5th stadium develop to the cocoon spinning stage and die in the cocoon, which results in innerside-stained cocoons (Nagata and Sun, 1998). An innerside-stained cocoon is soiled by a dead liquefying brownish larva or pupa and is no longer of commercial value. In sericultural farmhouses in Ibaraki Prefecture of Japan an outbreak of innerside-stained cocoons caused by BmNPV has often decreased the cocoon harvest. To avoid such an economic loss a careful disinfection of rooms, tools and other places related to silkworm rearing has to be done based on BmNPV epidemiology in the farmhouse and its surroundings. For that purpose a sensitive method to detect BmNPV in the sericultural environment is needed. To date BmNPV detection by fluoroimmunoassay, complement fixation assay, gel diffusion precipitating assay, sensitized latex agglutination assay, and enzyme-linked immunosorbent assay has been developed (Arakawa, 1994). These techniques utilize an antiserum developed against BmNPV or the pu-

* To whom correspondence should be addressed at: E-mail: arak@nias.affrc.go.jp DOI: 10.1303/aez.2005.105 
rified antibody from the serum. Noguchi et al. (1994, 1995) developed a BmNPV detection method using the polymerase chain reaction (PCR) with DNA primers designed on the basis of the viral genome DNA sequences. Immunological techniques requiring development of an antiserum accompanied by other experimental processes, and PCR techniques using expensive machinery are so intricate that they have hampered their worldwide practical use at farmhouses.

In the present study a sensitive bioassay for BmNPV with a process that is simple and easy to perform has been developed. This method utilizes $B$. mori larvae given an antifungal chitin synthesis inhibitor of agricultural use, Polyoxin AL wettable powder (Polyoxin AL). Ingestion of this agent by the silkworm results in a disappearance of the intestinal peritrophic membrane (PM), which implicates the loss of the intestinal barrier of the silkworm to pathogenic microorganisms (Arakawa, 2003; Tellam, 1996). Such a larva is easily infected by a low dose of BmNPV (Wang and Granados, 2001). By this method we were able to effectively detect BmNPV in the dust collected at 15 sericultural farmhouses in Ibaraki Prefecture.

\section{MATERIALS AND METHODS}

Insect and virus. Silkworm larvae of $B$. mori (Fuyoh $\times$ Tohkai) were reared on an artificial diet, Silkmate 2S (Nihon Nohsan Kogyo Ltd., Yokohama, Kanagawa) at $25^{\circ} \mathrm{C}$ with a long-day photoperiod (16L:8D). The BmNPV strain A 505 propagated in 5 th stadium $B$. mori larvae that had been used in a previous study (Arakawa, 2002; Arakawa and Sugiyama, 2002) was used in this study.

Effects of a chitin synthesis inhibitor and low temperature. Polyoxin AL, a chitin synthesis inhibitor, consisting of $10 \%$ polyoxin complex and 90\% additives was purchased from Kaken Pharmaceutical Ltd. (Fujieda, Shizuoka). Polyoxin AL was emulsified in distilled water and mixed with an artificial diet Silkmate $2 \mathrm{~S}$ and kneaded on a dish, resulting in $0.5 \%(\mathrm{w} / \mathrm{w})$ of this agent. Newly exuviated $2 \mathrm{nd}$, 3rd and 4th stadium larvae were assayed for BmNPV infection using the inclusion body of this virus after they had been fed a diet containing $0.5 \%$ Polyoxin $\mathrm{AL}$ for $24 \mathrm{~h}$ at $25^{\circ} \mathrm{C}$. Ayuzawa and Furuta (1966) reported that a silkworm exposed to low temperature just after ecdysis became susceptible to peroral infection by nucleopolyhedrovirus. To compare the effect on the viral infection of an exposure to low temperature with that of Polyoxin AL-ingestion, newly exuviated 2nd stadium larvae were chilled at $4^{\circ} \mathrm{C}$ for $19 \mathrm{~h}$ and then assayed for viral infection using the inclusion body. BmNPV inclusion bodies were inoculated perorally to the larvae as follows. Dried mulberry leaf powder $(0.2 \mathrm{~g})$ was mixed with $400 \mu \mathrm{l}$ of $10 \%(\mathrm{w} / \mathrm{w})$ sucrose solution and $100 \mu \mathrm{l}$ of BmNPV inclusion body suspension. Ten 2 nd, $3 \mathrm{rd}$ and 4 th stadium larvae were fed a mixture of $0.12,0.35$ and $0.70 \mathrm{~g}$, respectively. Inclusion bodies in the mixture ranged from 9.03 to $9.03 \times 10^{7} / \mathrm{g}$ in tenfold dilution steps. Ten larvae were submitted to assay at each of the viral concentration steps, and the assay was replicated three times. The larvae were served an artificial diet of Silkmate $2 \mathrm{~S}$ after they had been left for $24 \mathrm{~h}$ with the mixture and had completely consumed it. Larvae were then reared for $5 \mathrm{~d}$ at $26^{\circ} \mathrm{C}$, afterwhich larvae which had died by nucleopolyhedrosis were counted. The median lethal concentration $\left(\mathrm{LC}_{50}\right)$ of the BmNPV inclusion body was calculated by probit analysis using a computer program PriProbit (ver. 1.63) designed by Dr. M. Sakuma, Kyoto University, Kyoto, Japan. In this program, the homogeneity of estimates was examined by a $\chi^{2}$-test on the Sum of Squares between observed and expected frequencies (Pearson's $\chi^{2}$ test).

Detection of BmNPV in the dust of farmhouses. The dust collected at 15 sericultural farmhouses in Ibaraki Prefecture in the spring season of sericulture in 2003 was assayed for BmNPV. The farmhouse rooms and tools were disinfected with formalin just after the last sericultural season had ended in the late autumn of 2002, and were formalinised again before the first silkworm rearing started in the spring of 2003. Newly ecdysed 4th stadium silkworms were carried into the disinfected farmhouse and reared on mulberry leaves for about 3 weeks until they spun cocoons. Mulberry leaves were harvested twice a day and carried into a leaf storage space and stored there temporarily, then served to the silkworms in a rearing room. Full-grown silkworms in an almost wandering stage were transferred to a mounting room where they were mounted to the cocooning frame and spun cocoons. The farmhouse was forma- 
linised again after the cocoons had been harvested. Dust samples were collected prior to the beginning of the silkworm rearing in 2003 after the formalinisation and immediately after harvesting the cocoons before the re-formalinisation at a leaf storage space, a rearing room and a mounting room using a broom and a dustpan. A new sterilized broom and dustpan were used in every room to collect the dust. Each of the dust samples was divided into two aliquots and assayed for BmNPV in two ways. One aliquot was assayed by a conventional method that has been used in Ibaraki Prefecture and the other was submitted to a newly developed assay using Polyoxin AL (polyoxin assay) as follows.

Conventional assay: a dust sample ( $1 \mathrm{~g}$ ) was mixed with $10 \mathrm{ml}$ of $25 \mathrm{~mm}$ sodium pyrophosphate in a $50 \mathrm{ml}$ tube, and the mixture was stored at $4^{\circ} \mathrm{C}$ for $24 \mathrm{~h}$ after it had been lightly shaken by hand. BmNPV inclusion bodies attached to soils and plant debris were detached from them by this treatment (Fukuhara, 1982). Then the supernatant was applied onto an artificial diet, Silkmate $2 \mathrm{~S}$ $(20 \times 40 \times 5 \mathrm{~mm})$, to contaminate the entire surface of the diet except for the underside and fed to 20 newly exuviated silkworms in the 2 nd stadium. A fresh diet was served to the silkworms after they had fed on the diet contaminated by the supernatant for $24 \mathrm{~h}$ at $25^{\circ} \mathrm{C}$. Larvae that had died by nucleopolyhedrosis were counted after $5 \mathrm{~d}$, and the inclusion body of BmNPV in their milky whitish hemolymph was examined microscopically.

Polyoxin assay: a dust sample ( $1 \mathrm{~g})$ was mixed with a $10 \mathrm{ml}$ solution containing $100 \mathrm{~mm}$ sodium pyrophosphate and $10 \mathrm{~mm}$ sodium dihydrogenphosphate in a $50 \mathrm{ml}$ tube, and the mixture was shaken for $20 \mathrm{~min}$ on a horizontal rotating shaker at 120 cycles/min. A piece of Silkmate $2 \mathrm{~S}$ weighing about $3.5 \mathrm{~g}$ was put in the muddy mixture to contaminate its surface with the dust and then served to 10 2nd stadium silkworms that had ingested $0.5 \%$ Polyoxin AL in a diet for $24 \mathrm{~h}$ prior to this assay as described above. The silkworms were reared for $5 \mathrm{~d}$ at $26^{\circ} \mathrm{C}$ without being supplied with a fresh diet, and the larvae that had died by nucleopolyhedrosis were counted. The inclusion body in their milky whitish hemolymph was examined microscopically. The assay was replicated four times.

Occurrence of the innerside-stained cocoons at farmhouses. The occurrence of the innerside- stained cocoons in the spring season of sericulture in 2003 was examined at 15 farmhouses in Ibaraki Prefecture where dust was collected for a BmNPV assay. Five hundred cocoons were collected at random immediately after harvest, left as they were for several days and then examined for the inner brownish staining caused by the dead larva or pupa. The remains of the liquefying corpse in the cocoon were smeared on a slide glass and processed for a specific staining of a BmNPV inclusion body with buffalo black 12B according to Evans and Shapiro (1997).

\section{RESULTS}

\section{BmNPV infection in chilled or Polyoxin AL- treated silkworms}

Results from three replicates were treated as one sample for calculating the $\mathrm{LC}_{50}$ because similar results were obtained in the replicates. $\mathrm{LC}_{50}$ and its 95\% confidence limits of the BmNPV inclusion body in the silkworm are shown in Table 1. The $\mathrm{LC}_{50}$ value of the 2 nd stadium silkworm without any treatment was $2.83 \times 10^{5}$ inclusion bodies $/ g$ diet. Chilling the larvae at $4^{\circ} \mathrm{C}$ for $19 \mathrm{~h}$ and a peroral administration of $0.5 \%$ Polyoxin $\mathrm{AL}$ for $24 \mathrm{~h}$ decreased the $\mathrm{LC}_{50}$ value to $8.84 \times 10^{3}$ and $6.62 \times 10^{2}$, respectively, which indicates that BmNPV was detected more efficiently in the silkworm treated by $0.5 \%$ Polyoxin $\mathrm{AL}$ than in the chilled silkworm. $\mathrm{LC}_{50}$ values of $0.5 \%$ Polyoxin AL-treated $3 \mathrm{rd}$ and 4th stadium larvae were $1.75 \times 10^{2}$ and $2.21 \times 10^{1}$, respectively. These results indicate that the detection efficiency of BmNPV in the silkworm treated with Polyoxin AL increases as the silkworm develops.

\section{Contamination of farmhouses by BmNPV}

The number of innerside-stained cocoons occurring at 15 farmhouses in the spring season of sericulture in 2003 and the number of cocoons in which BmNPV was detected by buffalo black 12Bstaining are shown in Table 2. The data are arranged in decreasing order of the numbers of cocoons in which BmNPV was detected. Two to 35 cocoons were inside-stained in 500 specimens randomly collected at each of the 15 farmhouses. The number of the cocoons in which BmNPV was detected ranged from 0 to 28 . These results suggest that the innerside-stained cocoons occurred not 
Table 1. Enhanced infection of BmNPV in the 2nd, 3rd and 4th stadium B. mori larvae ingesting $0.5 \%$ Polyoxin $\mathrm{AL}$ or chilled at $4{ }^{\circ} \mathrm{C}$

\begin{tabular}{|c|c|c|c|c|c|c|}
\hline Larval stadium & $\begin{array}{l}\text { Treatment prior to } \\
\text { viral inoculation }\end{array}$ & $\begin{array}{c}\mathrm{LC}_{50} \text { of } \mathrm{BmNPV} \\
\text { (Inclusion bodies/g } \\
\text { diet) }\end{array}$ & $95 \%$ confidence limits & $\mathrm{df}^{\mathrm{a}}$ & $\chi^{2}$ & $\chi^{2}$-test $\mathrm{t}^{\mathrm{b}}$ \\
\hline Second & No & $2.83 \times 10^{5}$ & $1.43 \times 10^{5}-3.94 \times 10^{5}$ & 4 & 5.996 & $p>0.05$ \\
\hline Second & Chilled at $4^{\circ} \mathrm{C}$ & $8.84 \times 10^{3}$ & $4.87 \times 10^{3}-1.58 \times 10^{4}$ & 4 & 2.930 & $p>0.05$ \\
\hline Second & $\begin{array}{l}\text { Ingestion of } \\
0.5 \% \text { Polyoxin } \mathrm{AL}\end{array}$ & $6.62 \times 10^{2}$ & $3.40 \times 10^{2}-1.25 \times 10^{3}$ & 4 & 5.891 & $p>0.05$ \\
\hline Third & $\begin{array}{l}\text { Ingestion of } \\
0.5 \% \text { Polyoxin AL }\end{array}$ & $1.75 \times 10^{2}$ & $9.35 \times 10^{1}-3.15 \times 10^{2}$ & 4 & 4.339 & $p>0.05$ \\
\hline Fourth & $\begin{array}{l}\text { Ingestion of } \\
0.5 \% \text { Polyoxin AL }\end{array}$ & $2.21 \times 10^{1}$ & $6.97 \times 10^{0}-4.87 \times 10^{1}$ & 2 & 2.351 & $p>0.05$ \\
\hline
\end{tabular}

${ }^{a}$ Degrees of freedom.

${ }^{\mathrm{b}}$ The homogeneity of estimates was examined by a $\chi^{2}$-test on the Sum of Squares between observed and expected frequencies (Pearson's $\chi^{2}$-test).

Table 2. Detection of BmNPV in the dust collected at farmhouses where innerside-stained cocoon occurred

\begin{tabular}{|c|c|c|c|c|c|c|c|c|c|c|c|c|c|c|}
\hline \multirow{4}{*}{$\begin{array}{l}\text { Farmhouse } \\
\text { no. }\end{array}$} & & & \multicolumn{12}{|c|}{$\begin{array}{l}\text { No. of silkworms that died of nucleopolyhedrosis which were administered } \\
\text { the dust collected at the indicated timing }{ }^{\text {b }}\end{array}$} \\
\hline & \multicolumn{2}{|c|}{$\begin{array}{l}\text { No. of innerside-stained } \\
\text { cocoons }^{\mathrm{a}}\end{array}$} & \multicolumn{6}{|c|}{$\begin{array}{l}\text { Immediately before the beginning } \\
\text { of silkworm rearing }\end{array}$} & \multicolumn{6}{|c|}{$\begin{array}{l}\text { Immediately after harvesting } \\
\text { cocoons }\end{array}$} \\
\hline & \multirow[t]{2}{*}{ Total } & \multirow[t]{2}{*}{ NPV-detected ${ }^{\mathrm{c}}$} & \multicolumn{3}{|c|}{ Polyoxin assay } & \multicolumn{3}{|c|}{ Conventional assay } & \multicolumn{3}{|c|}{ Polyoxin assay } & \multicolumn{3}{|c|}{ Conventional assay } \\
\hline & & & LS & $\mathrm{RR}$ & MR & LS & $\mathrm{RR}$ & MR & LS & $\mathrm{RR}$ & MR & LS & $\mathrm{RR}$ & MR \\
\hline 1 & 35 & 28 & 2 & 23 & 38 & 0 & 0 & 0 & 2 & 31 & 36 & 0 & 0 & 0 \\
\hline 2 & 25 & 14 & 1 & 1 & 0 & 0 & 0 & 0 & 20 & 17 & 32 & 0 & 0 & 0 \\
\hline 3 & 24 & 8 & 2 & 0 & 39 & 0 & 0 & 2 & 36 & 34 & 39 & 0 & 0 & 0 \\
\hline 4 & 22 & 6 & 0 & 0 & 0 & 0 & 0 & 0 & 10 & 1 & 25 & 1 & 1 & 1 \\
\hline 5 & 19 & 5 & $\simeq^{\mathrm{d}}$ & - & - & - & - & - & 37 & 10 & 4 & 0 & 0 & 0 \\
\hline 6 & 12 & 4 & 0 & 3 & 1 & 0 & 0 & 0 & 27 & 23 & 16 & 0 & 1 & 0 \\
\hline 7 & 24 & 3 & 0 & 0 & 1 & 0 & 0 & 0 & 39 & 35 & 40 & 0 & 0 & 1 \\
\hline 8 & 17 & 1 & - & - & - & - & - & - & 32 & 12 & 27 & 1 & 0 & 1 \\
\hline 9 & 7 & 1 & 6 & 0 & 8 & 1 & 0 & 0 & 22 & 34 & 32 & 0 & 3 & 1 \\
\hline 10 & 6 & 1 & 1 & 0 & 1 & 0 & 0 & 0 & 0 & 0 & 38 & 0 & 0 & 0 \\
\hline 11 & 26 & 0 & 0 & 0 & 0 & 0 & 0 & 0 & 10 & 0 & 23 & 0 & 0 & 0 \\
\hline 12 & 14 & 0 & 0 & 0 & 22 & 0 & 0 & 0 & 0 & 0 & 18 & 0 & 0 & 1 \\
\hline 13 & 8 & 0 & 0 & 0 & 0 & 0 & 0 & 0 & 0 & 0 & 0 & 0 & 0 & 0 \\
\hline 14 & 7 & 0 & 0 & 0 & 14 & 0 & 0 & 0 & 4 & 2 & 33 & 0 & 0 & 1 \\
\hline 15 & 2 & 0 & 0 & 0 & 1 & 0 & 0 & 0 & 0 & 0 & 1 & 0 & 0 & 0 \\
\hline
\end{tabular}

a 500 randomly selected cocoons were examined at each of the farmhouses.

${ }^{\mathrm{b}}$ Forty and 20 larvae were used in each assay to detect the BmNPV in the dust that was collected at a leaf storage space (LS), a rearing room $(\mathrm{RR})$ and a mounting room $(\mathrm{MR})$ in the polyoxin assay and the traditional assay, respectively.

${ }^{\mathrm{c}} \mathrm{BmNPV}$ inclusion bodies were detected by buffalo black 12B-staining.

${ }^{\mathrm{d}}$ Dust was not collected.

only due to BmNPV but also to some other pathogens not identified here. The results of BmNPV detection in the dust of the leaf storage space (LS), the rearing room (RR) and the mount- ing room (MR) of the farmhouses are also shown in Table 2 in which the results of four replicates of the polyoxin assay are treated as one sample. In a conventional assay using silkworms not treated by 
Polyoxin AL, only a few larvae died by nucleopolyhedrosis. However, the polyoxin assay utilizing a silkworm that had ingested $0.5 \%$ Polyoxin AL detected BmNPV effectively. In the farmhouses from No. 1 to No. 10 at which the innerside-stained cocoon by BmNPV occurred, the conventional assay detected BmNPV in only 2 out of 8 farmhouses by using the dust collected before the beginning of the silkworm rearing, and in 5 out of 10 by using the dust collected after harvesting cocoons. On the other hand, the polyoxin assay detected BmNPV in 7 out of 8 farmhouses by using the dust collected before the beginning of silkworm rearing, and in all the farmhouses by using the dust collected after harvesting cocoons.

Some aspects of BmNPV contamination in the farmhouses were shown by the polyoxin assay. Although the farmhouses had been disinfected twice with formalin prior to collecting the dust immediately before the beginning of silkworm rearing, active BmNPV was detected in those farmhouses. BmNPV had remained mainly in the MR. More larvae were infected in the assay using the dust collected after harvesting cocoons than in the assay using the dust collected before the beginning of the silkworm rearing. From these data, it is recognized that the BmNPV accumulated even in only one cycle of silkworm rearing of about 3 weeks. These characteristics of BmNPV contamination in the farmhouse could not be demonstrated by the conventional assay. A regression line was made between the number of NPV-detected innersidestained cocoons ( 0 to 28 in Table 2$)$ and the total number of the dead larvae (LS+RR+MR in Table 2) treated with dust from each farmhouse. The number of NPV-detected innerside-stained cocoons shows a significant positive correlation with the number of NPV-infected larvae by the polyoxin assay using the dust collected before the beginning of the silkworm rearing $(r=0.71, \mathrm{df}=11, p<0.05)$ but not with that by the polyoxin assay using the dust collected after harvesting cocoons $(r=0.34$, $\mathrm{df}=13, p>0.05)$. No significant correlation was detected using the data by the conventional assay $(r=0.03, \mathrm{df}=11$ for dust before rearing silkworms; $r=-0.23, \mathrm{df}=13$ for dust after harvesting cocoon).

\section{DISCUSSION}

This study presents a new hypersensitive bioas- say of BmNPV utilizing the silkworm that ingested $0.5 \%$ Polyoxin $\mathrm{AL}$, an antifungal agent of agricultural use, in a diet prior to a peroral inoculation of a sample to be examined. An ingestion of Polyoxin AL by a silkworm promotes BmNPV infection more effectively than chilling the silkworm does. This assay is suitable for practical use in a sericultural farmhouse because the procedure of this assay is easy to carry out without any expensive machinery and reagents. If there is a place where pathogens tend to accumulate in a sericultural farmhouse, which may become an origin of virus supply, such a place must be disinfected carefully. A place with a contamination by BmNPV can be detected by assaying the dust there. And whether or not sterilization has been done perfectly could be checked accurately by assaying the dust there again by the polyoxin assay. The $\mathrm{LC}_{50}$ of the silkworm larvae ingesting Polyoxin AL decreases as they develop. Thus, use of 4th stadium larvae is recommended when an especially effective detection is required. On the other hand, the second stadium silkworm would be suitable when treating a large number of samples. Silkworms at the 2nd stadium that had ingested Polyoxin AL were used to detect BmNPV in the dust from 15 sericultural farmhouses. Dust samples were collected at a leaf storage space, a rearing room and a mounting room just before the beginning of the silkworm rearing after the formalinisation of the rearing environment. The dust was collected again at the same places immediately after harvesting the cocoons. In addition to the BmNPV detection in the dust, occurrence of the innerside-stained cocoons was examined at the same 15 farmhouses where the dust was collected. The following features of BmNPV contamination are recognized. In some farmhouses, BmNPV was not inactivated even after treatment of formalin. BmNPV accumulated in only one cycle of the silkworm rearing of about 3 weeks in almost all the farmhouses. Of all the three places in which the dust was assayed, the mounting room tended to be most heavily contaminated by BmNPV. More innerside-stained cocoons occurred in a farmhouse where more silkworms died of BmNPV in an assay of the dust collected before the beginning of the silkworm rearing. On the other hand, these features of BmNPV contamination were not detected using the silkworm larvae that had not ingested Polyoxin AL. Thus, this assay 
with Polyoxin AL should become an effective tool to study the epidemiology of BmNPV.

The polyoxin assay would be able to accurately monitor the pathogenic potentials in the sericultural environment because it only detects active virus. An assay using antisera against a virus detects not only active virus but also remaining antigenicity of virus that has been inactivated by formalinisation. The PCR technique also detects formalin-inactivated virus that still retains an intact DNA sequence to be detected specifically. Therefore, the polyoxin assay is an effective tool to assess the cleanliness of the sericultural environment, in regard to monitoring active viruses.

In the polyoxin assay the procedure dealing with the dust was slightly modified compared to that of the conventional assay. In the conventional assay the muddy suspension of the dust in a sodium pyrophosphate solution had been settled at $4^{\circ} \mathrm{C}$ for $24 \mathrm{~h}$. Then the supernatant of the suspension was applied onto an artificial diet without stirring to be ingested by a silkworm. There was concern that BmNPV inclusion bodies might precipitate by terrestrial gravitation while the suspension was being placed for $24 \mathrm{~h}$ because the specific gravity of the BmNPV inclusion body is 1.268 (Kawase, 1976). Further, the supernatant of the suspension would certainly have less inclusion bodies than the number that the suspension had before it was placed. In the polyoxin assay this step of placing at $4^{\circ} \mathrm{C}$ for $24 \mathrm{~h}$ was eliminated and the artificial diet to be ingested by the silkworm was immersed directly in the muddy suspension of the dust. This method should result in an increased contamination of the diet by BmNPV inclusion bodies than by using the supernatant after placing. This modification of the assay procedure will also contribute to the effectiveness of the BmNPV detection in the polyoxin assay, in addition to the utilization of a silkworm to which Polyoxin AL was administered. In the polyoxin assay the dust was suspended in saline with a higher salt concentration than that in the conventional assay. The effect of this modification on viral detection is uncertain in this study.

Infection of a cypovirus of B. mori (BmCPV) is also promoted by ingestion of Polyoxin AL by the host (personal communication from Dr. Y. Furuta). The pathology of BmCPV in the silkworm progresses more slowly than that of BmNPV. In this study the infection of BmNPV was assessed $5 \mathrm{~d}$ after the silkworms had been fed a diet contaminated by farmhouse dust. If the silkworms are reared for $7 \mathrm{~d}$ or longer, the infection of BmCPV will probably be recognized in the larvae that remain after the larvae that had died by nucleopolyhedrosis are removed. On the other hand, the detection of infectious flacherie virus and densovirus by an bioassay is not affected by Polyoxin AL because it does not promote the infection of these viruses in $B$. mori larvae (personal communication from Dr. Y. Furuta).

Captan (an antifungal chitinase inhibitor), nikkomycin Z (an antibiotic inhibiting chitin synthesis), flufenoxuron (an insect growth regulator inhibiting insect cuticle synthesis) and Tinopal UNPA-GX (i.e. fluorescent brightener 28, an optical brightener binding to a chitin fiber) were reported to promote BmNPV infection in B. mori larvae, as did Polyoxin AL (Arakawa et al., 2000; Arakawa and Sugiyama, 2002; Arakawa, 2003). A peritrophic membrane (PM) is not observed in the gut of the silkworm ingesting those chemicals. Even if a PM is detected it is more fragile than that in normal larvae (Arakawa, 2002). Those chemicals would be able to substitute for Polyoxin AL in the bioassay developed in this study.

\section{REFERENCES}

Arakawa, A. (1994) Studies on the serological diagnosis of silkworm virus diseases and its application to epidemiological survey of cytoplasmic polyhedrosis virus dissemination in sericultural farms. Bull. Fukushima Seric. Exp. Stn. 27: 1-84 (in Japanese with English summary).

Arakawa, T. (2002) Promotion of nucleopolyhedrovirus infection in larvae of the silkworm, Bombyx mori (Lepidoptera: Bombycidae) by flufenoxuron. Appl. Entomol. Zool. 37: 7-11.

Arakawa, T. (2003) Chitin synthesis inhibiting antifungal agents promote nucleopolyhedrovirus infection in silkworm, Bombyx mori (Lepidoptera: Bombycidae) larvae. J. Invertebr. Pathol. 83: 261-263.

Arakawa, T., M. Kamimura, Y. Furuta, M. Miyazawa and M. Kato (2000) Peroral infection of nuclear polyhedrosis virus budded particles in the host, Bombyx mori L., enabled by an optical brightener, Tinopal UNPA-GX. $J$. Virol. Meth. 88: 145-152.

Arakawa, T. and M. Sugiyama (2002) Promotion of nucleopolyhedrovirus infection in larvae of the silkworm Bombyx mori (Lepidoptera: Bombycidae) by an antibiotic, nikkomycin Z. Appl. Entomol. Zool. 37: 393-397.

Ayuzawa, C. and Y. Furuta (1966) Susceptibility of the silkworm (Bombyx mori L.) to the nuclear polyhedrosis virus and the role of the inhibiting activity of the gut-juice. $J$. Seric. Sci. Jpn. 35: 66-70 (in Japanese with English sum- 
mary).

Evans, H. and M. Shapiro (1997) Viruses. In Manual of Techniques in Insect Pathology (L. A. Lacey ed.). Academic Press, New York, pp. 17-53.

Fukuhara, T. (1982) Purification of a nuclear polyhedrosis virus from soil and their identification. Jpn. J. Appl. Entomol. Zool. 26: 183-187 (in Japanese with English summary).

Kawase, S. (1976) Viruses and Insects. Nankohdoh, Tokyo. 282 pp. (in Japanese).

Nagata, M. and P. J. Sun (1998) Multiplication of nuclear polyhedrosis virus in the silkworm larvae during the latter period of the 5th-instar. J. Seric. Sci. Jpn. 67: 23-29 (in Japanese with English summary).

Noguchi, Y., M. Kobayashi and T. Shimada (1994) An appli- cation of the polymerase chain reaction for practical diagnosis of the nuclear polyhedrosis in large-scale culture of Bombyx mori. J. Seric. Sci. Jpn. 63: 399-406 (in Japanese with English summary).

Noguchi, Y., M. Kobayashi and T. Shimada (1995) An improved method for PCR-based detection of nuclear polyhedrosis virus in Bombyx mori. J. Seric. Sci. Jpn. 64: 352-359 (in Japanese with English summary).

Tellam, R. L. (1996) The peritrophic matrix. In Biology of the Insect Midgut (M. J. Lehane and P. E. Billingsley eds.). Chapman and Hall, London, pp. 86-114.

Wang, P. and R. R. Granados (2001) Molecular structure of the peritrophic membrane (PM): identification of potential PM target sites for insect control. Arch. Insect Biochem. Physiol. 47: 110-118. 